\title{
SARCOMA DE KAPOSI E SÍNDROME DA IMUNODEFICIÊNCIA ADQUIRIDA: CARACTERÍSTICAS DESTA ASSOCIAÇÃO, INCLUINDO NOVOS CONCEITOS SOBRE PATOGÊNESE E TRATAMENTO
}

\author{
KAPOSI'S SARCOMA AND ACQUIRED IMMUNODEFICIENCY SYNDROME: CHARACTERISTICS OF \\ THIS ASSOCIATION INCLUDING NEW CONCEPTS ON PATHOGENESIS AND TREATMENT
}

\author{
Benedito A.L. Fonseca ${ }^{1}$, Valdes R. Bollela² \& Roberto da Justa P. Neto ${ }^{2}$
}

\begin{abstract}
1Docente do Departamento de Clínica Médica - Divisão de Moléstias Infecciosas e Tropicais; ${ }^{2}$ Médico Assistente da Unidade Especial de Tratamento de Doenças Infecciosas. Hospital das Clínicas da Faculdade de Medicina de Ribeirão Preto da Universidade de São Paulo. Correspondência: Prof.Dr. Benedito Antonio Lopes Fonseca - Departamento de Clínica Médica da Faculdade de Medicina de Ribeirão Preto da Universidade de São Paulo - Av. Bandeirantes, 3900 - CEP: 14048-900 - Ribeirão Preto - SP. Fax: (016) 6336695.
\end{abstract}

FONSECA BAL; BOLLELA VR \& NETO RJP. Sarcoma de Kaposi e síndrome da imunodeficiência adquirida: características desta associação, incluindo novos conceitos sobre patogênese e tratamento. Medicina, Ribeirão Preto, 32: 26-39, jan./mar. 1999.

RESUMO: No início da década de 80, a síndrome da imunodeficiência adquirida foi reconhecida e descrita em homossexuais jovens, do sexo masculino, previamente saudáveis, acometidos por pneumopatia atípica causada por microorganismo oportunista, identificado como sendo o Pneumocystis carinii, e com lesões cutâneas vinhosas, nodulares, cujo estudo histopatológico revelou tratar-se de Sarcoma de Kaposi. O Sarcoma de Kaposi é a neoplasia mais freqüente em pacientes com infecção pelo vírus da imunodeficiência humana. Apesar de não totalmente esclarecida, sua fisiopatogenia tem sido associada à presença de um herpes vírus, de provável transmissão sexual, que estaria implicado no surgimento da doença. Esta revisão busca atualizar conceitos da fisiopatologia e tratamento desta condição grave e freqüente associada à infecção pelo HIV.

UNITERMOS: Síndrome de Imunodeficiência Adquirida. Sarcoma de Kaposi. Patogenia. Tratamento.

\section{INTRODUÇÃO}

Morris Kaposi, no ano de 1872, descreveu uma nova patologia que acometia, predominantemente, idosos, do sexo masculino, com lesões múltiplas, hiperpigmentadas, nodulares e de ocorrência mais freqüente nas extremidades dos membros inferiores. Inicialmente, foi denominada "Sarcoma hiperpigmentado, múltiplo, idiopático, da pele"(1), e, mais tarde, passaria a ser conhecida como Sarcoma de Kaposi (SK) ${ }^{(2)}$. Desde então, foram descritas quatro (4) formas clínicas de apresentação dessa doença. A descrição feita por Morris Kaposi, no século passado, caracteriza a "forma clássica" do SK, bastante rara, sendo mais preva- lente na América do Norte e Europa, acometendo homens idosos descendentes de judeus do Leste Europeu ou de povos da região do Mar Mediterrâneo ${ }^{(3)}$. A "forma endêmica" do SK, presente no Continente Africano, principalmente nas regiões ao sul do Deserto do Saara, é também relativamente rara, porém mais agressiva, e acomete adultos jovens e crianças negras $^{(4)}$. Em meados da década de setenta (70), com o advento dos transplantes renais e suas terapias de imunossupressão, bem como com o surgimento de tratamento quimioterápico para algumas neoplasias, observou-se um aumento importante na incidência de SK, diretamente associado à imunodeficiência severa. Essa forma passou a ser denominada de "iatro- 
gênica"(5). Por fim, uma forma similar do SK, mais agressiva, muitas vezes associada à pneumonia por Pneumocystis carinii, passou a ser notada no início da década de oitenta (80) entre adultos jovens, do sexo masculino, homossexuais ou bissexuais, de algumas cidades dos Estados Unidos. É o que se denominaria de "forma epidêmica" do SK, que ocorre em indivíduos infectados pelo vírus da imunodeficiência humana $(\mathrm{HIV})^{(6)}$, sendo a malignidade mais comum de tal grupo $^{(7,8)}$ (Tabela I). Este artigo se concentrará na discussão desta última forma da doença (SK/SIDA).

\section{HISTÓRICO}

No início da década de oitenta (80), a Síndrome da Imunodeficiência Adquirida (SIDA/AIDS) foi reconhecida e descrita nos Estados Unidos. No verão de 1981, o Centro de Prevenção e Controle de Doenças (CDC) foi alertado para a ocorrência inexplicada de pacientes jovens, previamente saudáveis, do sexo masculino e de comportamento homossexual, sendo acometidos por pneumopatia atípica, causada por microorganismo oportunista, identificado como sendo o Pneumocystis carinii, e com lesões cutâneas, vinhosas, nodulares, cujo estudo histopatológico revelou tratar-se de Sarcoma de Kaposi ${ }^{(6)}$. O Sarcoma de Kaposi foi, portanto, uma das primeiras doenças oportunistas reconhecida na infecção pelo HIV e ainda é a neoplasia maligna mais comumente associada à SIDA.

\section{EPIDEMIOLOGIA}

Passados mais de quinze (15) anos desde a sua identificação, acumulou-se bastante informação sobre o SK como complicação da infecção pelo HIV, havendo progressos consideráveis na caracterização de sua epidemiologia. Dados de dois (2) importantes estudos epidemiológicos, recentemente concluídos, envolvendo seis mil, quinhentos e setenta e oito (6.578) pacientes de dezessete (17) países europeus ${ }^{(7)}$ e seiscentos e oitenta e sete (687) pacientes da Dinamar$\mathrm{ca}^{(8)}$, diagnosticados com SIDA, entre 1979 e 1990, complementaram informações prévias de outras partes do mundo e sedimentaram o conhecimento sobre a epidemiologia do SK na infecção pelo $\operatorname{HIV}^{(9,10)}$. Além disso, a recente compreensão sobre o modo de transmissão, a história natural e a epidemiologia da infecção pelo herpesvírus humano 8 (HVH 8), um agente envolvido na etiologia do SK, trouxe uma melhor compreensão sobre a doença ${ }^{(11)}$.

A idade média dos pacientes vítimas do SK/SIDA varia em torno de trinta e oito (38) anos, sendo que $69 \%$ dos casos ocorrem na faixa etária dos trinta (30) aos trinta e nove (39) anos. A relação de homens e mulheres acometidos varia entre 50 a $100: 1^{(12)}$. Seis por cento das crianças HIV(+) desenvolvem a doença, bem como $8 \%$ das mulheres soropositivas. Antes da década de oitenta (80) a incidência anual do SK era em torno de 0,021 a $0,061 / 100.000$ habitantes $^{(13)}$.

\begin{tabular}{|c|c|c|c|c|c|c|c|c|}
\hline Forma & $\begin{array}{l}\text { Idade } \\
\text { (Anos) }\end{array}$ & $\begin{array}{c}\text { População De } \\
\text { Risco }\end{array}$ & $\begin{array}{l}\text { Relação } \\
\text { Masc./Fem }\end{array}$ & $\begin{array}{l}\text { Lesão } \\
\text { Mucosa }\end{array}$ & Linfonodos & Vísceras & $\begin{array}{l}\text { Curso da } \\
\text { Doença }\end{array}$ & Sobrevida \\
\hline Clássico & $50-80$ & $\begin{array}{l}\text { Descendentes de } \\
\text { judeus do Leste } \\
\text { Europeu e do } \\
\text { Mediterrâneo }\end{array}$ & $10 / 1$ & Rara & Raro & Ocasional & $\begin{array}{c}\text { Lento } \\
\text { (>10 a } 15 \text { anos) }\end{array}$ & 10 a 15 anos \\
\hline $\begin{array}{l}\text { Endêmico } \\
\text { - Nodular }\end{array}$ & $25-40$ & $\begin{array}{l}\text { Adultos africanos, } \\
\text { negros }\end{array}$ & $17 / 1$ & Rara & Raro & Raro & $\begin{array}{c}\text { Lento } \\
\text { (>8 a } 10 \text { anos) }\end{array}$ & 8 a 10 anos \\
\hline - Florido & $25-40$ & $\begin{array}{l}\text { Adultos africanos, } \\
\text { negros }\end{array}$ & $17 / 1$ & Rara & Ocasional & Ocasional & Rápido & 3 a 5 anos \\
\hline - Agressivo & $25-40$ & $\begin{array}{l}\text { Adultos africanos, } \\
\text { negros }\end{array}$ & $17 / 1$ & Rara & Rara & Ocasional & $\begin{array}{l}\text { Rápido, } \\
\text { localizado }\end{array}$ & 5 a 8 anos \\
\hline - Linfadenopático & $1-15$ & $\begin{array}{l}\text { Crianças } \\
\text { africanas, negras }\end{array}$ & $1-3 / 1$ & Nunca & Sempre & Usual & $\begin{array}{l}\text { Rápido } \\
\text { disseminado }\end{array}$ & 1 a 3 anos \\
\hline $\begin{array}{l}\text { latrogênico } \\
\text { - Imunossuprimidos }\end{array}$ & $20-60$ & $\begin{array}{l}\text { Pacientes em uso } \\
\text { de drogas imunos- } \\
\text { supressoras }\end{array}$ & $2 / 1$ & Comum & Ocasional & Ocasional & Limitado & $\begin{array}{l}\text { Geralmente } \\
\text { regride, sus- } \\
\text { pendendo-se } \\
\text { medicação }\end{array}$ \\
\hline Epidêmico & $18-65$ & $\begin{array}{l}\text { Homens Homos- } \\
\text { sexuais (95\%) }\end{array}$ & $50-100 / 1$ & Comum & Comum & Comum & $\begin{array}{l}\text { Rapidamente } \\
\text { progressivo }\end{array}$ & $\begin{array}{l}\text { Depende da } \\
\text { doença de } \\
\text { base }\end{array}$ \\
\hline
\end{tabular}


Desde então, já se tem descritos vinte e quatro mil (24.000) casos da doença, notificados no CDC. Aproximadamente $26 \%$ dos homossexuais norte-americanos têm SK/SIDA ${ }^{(9)}$ e $15 \%$ de todos os diagnósticos de SIDA têm o SK associado ${ }^{(14)}$. No Brasil, até novembro de 1997, foram notificados pelo Ministério da Saúde seis mil, duzentos e sessenta e sete (6.267) casos de SK/SIDA ${ }^{(15)}$.

Na Europa, assim como no resto do mundo, a associação SK/SIDA é vista com maior freqüência em indivíduos do sexo masculino que no do sexo feminino. Indivíduos do sexo masculino com AIDS e comportamento homo/bissexual em particular desenvolvem SK. Ao final da doença, um terço dos homo/bissexuais masculinos, com SIDA, na Europa, desenvolveram $\mathrm{SK}^{(7,8)}$. Outros estudos também demonstraram que homens homo/bissexuais são aproximadamente vinte (20) vezes mais predispostos a desenvolverem SK do que hemofílicos e, além do mais, atividade sexual freqüente e certas práticas sexuais como o coito anal são associadas com o desenvolvimento de $\mathrm{SK}^{(11,16)}$. Observou-se que mulheres infectadas pelo HIV, parceiras sexuais de homens bissexuais com SK, tiveram risco aumentado de desenvolverem SK, quando comparadas com outros grupos de mulheres também HIV positivas $^{(16)}$. A forma de contágio da infecção pelo HIV também tem relação com um maior ou menor risco de desenvolvimento de SK. Indivíduos que contraíram a infecção pelo HIV por via sangüínea têm um risco substancialmente menor de desenvolver SK que aqueles que adquiriram o HIV por via sexual ${ }^{(8,16)}$. Isso pode ser explicado pela possível transmissão do HVH 8 através da via sexual.

Do ponto de vista clínico, o SK é uma neoplasia que pode desenvolver-se em qualquer fase da infecção pelo HIV, independente do grau de imunossupressão e do número de células CD4+. Entretanto, estudos mostraram que uma baixa contagem de células CD4+, no momento do diagnóstico de SIDA, prevê um risco aumentado de desenvolvimento de SK durante os próximos dois anos ${ }^{(7,8)}$. Fica, portanto, evidente o fato de que o Sarcoma de Kaposi também é uma condição oportunista e algum grau de imunossupressão favorece o aparecimento da doença como se observa para outras condições oportunistas de natureza infecciosa, relacionadas à SIDA, mas ela não é essencial para o aparecimento da doença. A proporção de homens homo/bissexuais que desenvolvem SK como primeira manifestação da SIDA sofreu queda de cerca de $30 \%$, antes de 1985 , para $13 \%$ em $1990^{(7)}$. O momento de aparecimento do SK como doença definidora de SIDA também mudou nos últimos anos, passando a ser diagnosticado mais tardiamente no curso da infecção crônica pelo HIV, provavelmente em decorrência da introdução da terapia anti-retroviral; conseqüentemente, o número de linfócitos CD4+ no momento do diagnóstico de SK também tem caído ${ }^{(7,17)}$. Entretanto, a proporção de homens homo/bissexuais com SIDA e SK, no momento do óbito, tem se mantido estável com o passar dos anos. Portanto, a ocorrência de SK se manteve constante com o tempo, mas tem sido associada com imunossupressão mais severa e aparecimento mais tardio no curso da SIDA, nos últimos anos.

No Brasil, os dados do Ministério da Saúde revelam um total de cento e vinte mil, trezentos e noventa e nove (120.399) casos notificados de Síndrome de Imunodeficiência Adquirida até novembro de 1997. Destes, seis mil, duzentos e sessenta e sete (6.267) ou 5,4\% apresentavam o diagnóstico de Sarcoma de Kaposi associado. Os dados, agrupados por períodos de tempo, mostram que, de 1980 a 1984, 17,9\% dos casos de SIDA tinham associado o diagnóstico de Sarcoma de Kaposi, no período de 1985 a 1987, 13,3\% e, de 1988 a $1997,5,1 \%{ }^{(15)}$.

Na região de Ribeirão Preto, interior do estado de São Paulo (DIR XVIII), foram notificados, até 1997, três mil, cento e cinquienta e três (3.153) casos de SIDA, sendo que, destes, sessenta e três (63) (2\%) tiveram diagnóstico de SK associado, a maioria na faixa etária dos vinte e cinco (25) aos quarenta (40) anos (63\%). Quanto à categoria de exposição, dezessete (17) eram homossexuais, seis (6) heterossexuais, seis (6) bissexuais, oito (8) usuários de droga endovenosa, um (1) hemofílico, quatro (4) homossexuais ou bissexuais e usuários de droga endovenosa, oito (8) heterossexuais promíscuos e adidos a drogas, nove (9) heterossexuais com parceiros múltiplos e quatro (4) de categoria ignorada ${ }^{(18)}$.

\section{APRESENTAÇÃO CLÍNICA}

O Sarcoma de Kaposi, em pacientes com SIDA, apresenta-se como tumores vinhosos, freqüentemente elevados. O local mais comum de acometimento inicial é a pele. Em alguns casos, porém, não há comprometimento cutâneo ou este é precedido por lesões viscerais, orais ou ganglionares ${ }^{(19)}$. O SK cutâneo tem preferência de distribuição para cabeça, pescoço e tronco e pode variar em número, observando-se desde algumas lesões isoladas até centenas de lesões disseminadas. As lesões cutâneas podem ser maculares, platiformes, papulares ou nodulares, com dimensões que variam de alguns milímetros até placas confluentes 
enormes ou nódulos de dez (10) centímetros ou mais ${ }^{(12,19,20)}$. As lesões são rosadas, vermelhas, purpúricas ou castanhas (Figuras 1 e 2). Nos indivíduos de cor negra, algumas lesões são muito escuras, quase negras. Ocasionalmente, o paciente pode desenvolver lesões no tronco, simétricas, bilateralmente, e ao longo das linhas de Langer, o que faz diagnóstico diferencial com ptiríase rósea ${ }^{(12)}$. A presença de edema nos membros inferiores, periorbital e de genitália externa é muito freqüente, associada a lesões nessas áreas. A gravidade do edema pode ser desproporcional à quantidade de lesões cutâneas presentes. Observou-se que trauma ou doenças cutâneas, prévias predisporiam ao aparecimento de lesões do SK, o qual foi denominado Fenômeno de Koebner ${ }^{(21)}$. Acometimento de orofaringe ocorre em cerca de um terço dos pacientes e a lesão mais frequiente é em palato duro. O SK também pode envolver gengiva, língua, amígdalas, faringe e traquéia, podendo interferir com a deglutição e a fonação, resultando na perda dos dentes ou obstrução das vias aéreas superiores ${ }^{(20)}$.

$\mathrm{O}$ envolvimento de linfonodos ocorre em mais da metade dos casos dos pacientes com SIDA. Os gânglios têm, geralmente, diâmetro de 1 a 2 cm, são endurecidos, parenquimatosos, móveis, de localização mais freqüente nas regiões inguinal e cervical $^{(12)}$.

O SK/SIDA, no trato gastrintestinal, ocorre com freqüência de aproximadamente $50 \%$, sendo mais comum no duodeno e, às vezes, aparece antes das lesões cutâneas. Também pode acometer estômago (lesões em placas e pólipos) e cólon (nódulos e lesões ulceradas). Na maioria dos casos, o comprometimento gastrintestinal é assintomático, porém o SK pode causar obstrução, sangramento e dor e envolver todos os segmentos do tubo digestivo. A biópsia não é sensível para diagnóstico de SK/SIDA em trato gastrintestinal, visto que o tumor é submucoso e esse exame só detecta 20 a $25 \%$ das lesões ${ }^{(19,22,23)}$.

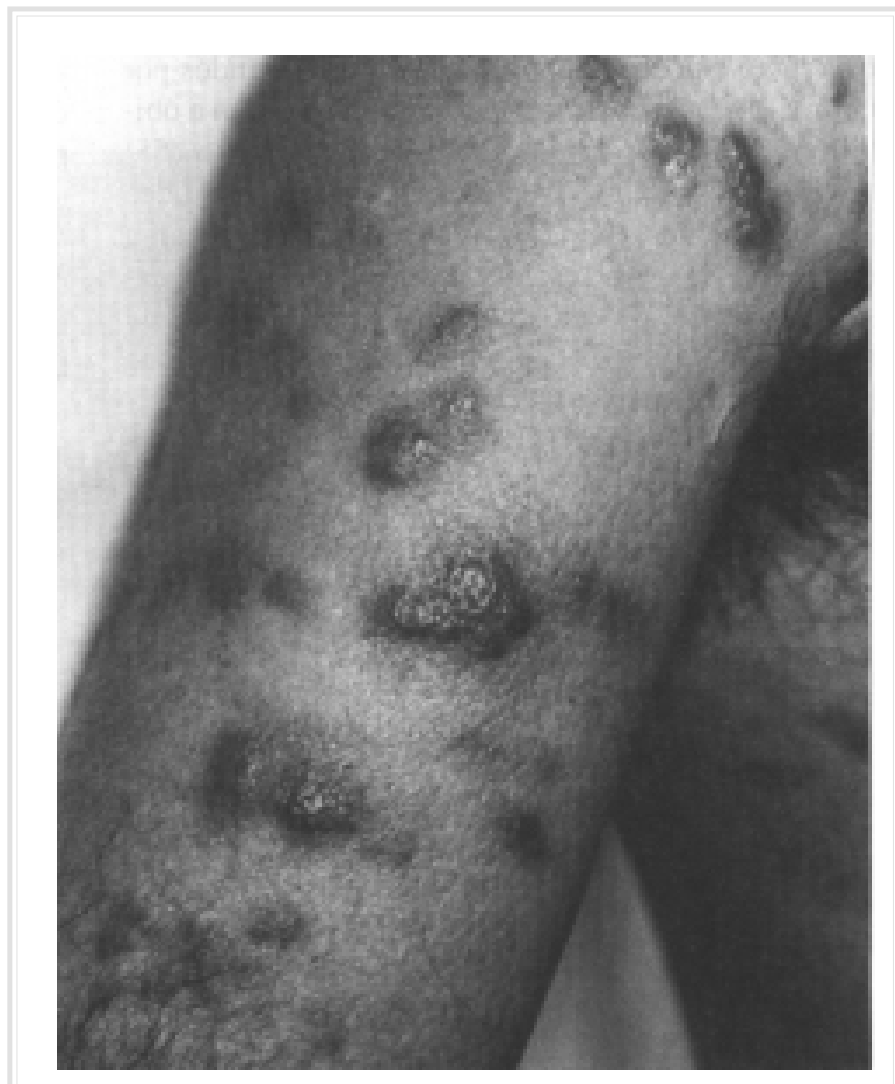

Figura 2: Lesões características do Sarcoma de Kaposi em membro superior de paciente HIV+. Note a característica nodular das lesões. 
O SK/SIDA pulmonar tem uma freqüência de ocorrência que varia entre 20 a $50 \%$ dos pacientes e raramente é sítio inicial da lesão. As lesões podem se localizar em parênquima pulmonar, árvore brônquica ou pleura e, em geral, são assintomáticas. Na árvore brônquica, pode se apresentar como placas e nódulos e, eventualmente, até obstruir as vias aéreas. O envolvimento da pleura ocorre em até $70 \%$ dos pacientes com SK pulmonar e leva à formação de derrame pleural, geralmente hemorrágico. A partir do diagnóstico de SK pulmonar, a sobrevida do paciente diminui consideravelmente, e o óbito ocorre por insuficiência respiratória. Devido à apresentação característica da lesão pulmonar à broncoscopia, geralmente, não é necessária biópsia para confirmar o diagnóstico, pois aumenta muito o risco de sangramento ${ }^{(24)}$.

Existem casos descritos de SK envolvendo vários outros órgãos internos, como fígado, baço, esqueleto, medula óssea, sistema nervoso central, coração e pericárdio, porém o diagnóstico de SK, nesses órgãos, só raramente é confirmado antes da morte do paciente ${ }^{(19)}$.

Apesar do SK/SIDA ser uma doença agressiva, a maioria dos pacientes vão a óbito por outras causas, principalmente infecção oportunista. Num estudo em que cento e doze (112) pacientes foram seguidos por quinze (15) meses, sessenta e cinco (65) foram a óbito nesse período, sendo que cinquenta e cinco (55) deles morreram devido a infecção oportunista e dez (10) pacientes faleceram tendo como causa uma neoplasia. Dois casos foram de linfoma e oito (8) casos atribuídos diretamente ao SK/SIDA, que, na maioria, tinha infiltração pulmonar do tumor, o que piorou sensivelmente o prognóstico, conforme já citado anteriormente ${ }^{(24,25)}$. A sobrevida dos pacientes com SK/
SIDA sem infecção oportunista, avaliada por Safai et al., foi de vinte e oito (28) meses a partir do diagnóstico, para $80 \%$ dos pacientes, comparada com $20 \%$ de sobrevida no mesmo período para pacientes com infecção oportunista associada. O principal determinante da sobrevida é a contagem de células CD4+ no momento do diagnóstico do SK/SIDA. Há pacientes com SK/AIDS em seguimento sem infecção oportunista com sobrevida de até dez (10) anos. Envolvimento visceral resulta em curta sobrevida, em média menos de seis (6) meses ${ }^{(26)}$. A história natural do SK pode seguir vários caminhos. O tumor pode se manter estável, com poucas lesões, sem repercussões, ou progredir. Aproximadamente metade dos pacientes acabam evoluindo para doença progressiva com disseminação das lesões cutâneas e envolvimento visceral ${ }^{(19,25)}$. Não se conhecem fatores preditivos de progressão da doença, exceto a infecção pelo herpesvírus tipo 8 , assunto que será comentado posteriormente.

\section{ESTADIAMENTO}

O estadiamento de lesões neoplásicas tem como finalidade proporcionar informações prognósticas, ser um guia terapêutico e simplificar a avaliação de dados. Existem vários sistemas de estadiamento, propostos para o SK/SIDA. O sistema mais amplamente utilizado foi o desenvolvido pelo AIDS Clinical Trial Group (Tabela II) e divide os pacientes em grupos de risco favorável ou desfavorável, de acordo com a extensão clínica do tumor (T), o estado imunológico, baseado na contagem de CD4+ (I), e a gravidade da doença sistêmica, causada pelo HIV, associada ou não a infecções oportunistas ou doenças sistêmicas $(S)^{(27)}$.

\section{Tabela II - Estadiamento do SK/SIDA de maior aceitação mundial

\begin{tabular}{|c|c|c|}
\hline & $\begin{array}{l}\text { Risco Melhor }(0) \\
\text { (Todos os que seguem) }\end{array}$ & $\begin{array}{c}\text { Risco Pior (1) } \\
\text { (Qualquer um dos que seguem) }\end{array}$ \\
\hline Tumor $(T)$ & $\begin{array}{l}\text { - Lesão confinada à pele ou linfonodos; e/ou } \\
\text { - Mínima lesão oral (confinada ao palato) }\end{array}$ & $\begin{array}{l}\text { - Edema ou ulceração associada ao tumor } \\
\text { - Extensa lesão oral } \\
\text { - S.K. gastrintestinal ou em outra víscera }\end{array}$ \\
\hline Sistema Imune (I) & - Células CD4 $\geq 200 / \mathrm{mm}^{3}$ & - Células CD4 <200/mm ${ }^{3}$ \\
\hline Doenças Sistêmicas (S) & $\begin{array}{l}\text { - Sem história prévia de infecção oportunista } \\
\text { - Ausência de Sintomas "B"* } \\
\text { - "Status" Karnofsky } \geq 70\end{array}$ & $\begin{array}{l}\text { - História prévia de infecção oportunista } \\
\text { - Presença de sintomas "B" } \\
\text { - Karn ofsky < } 70 \\
\text { - Outras doenças relacionadas ao HIV } \\
\text { (neurológicas, linfoma, etc...) }\end{array}$ \\
\hline
\end{tabular}

Adaptado de Krown S et al. Kaposi's Sarcoma in the acquired immunodeficiency syndrome: a proposal for uniform evaluation, response and staging criteria(27)

* Sintomas "B": febre, sudorese noturna, perda de peso de mais de 10\%, diarréia persistente, por mais de duas semanas. 


\section{DIAGNÓSTICO DIFE- RENCIAL}

O diagnóstico diferencial do SK/SIDA inclui, entre outras, angiomatose bacilar, linfoma cutâneo, hemangioma hemosiderótico, linfangioendotelioma benigno, acroangiodermatite, angiosarcoma cutâneo, hemangioendotelioma de células fusiformes, angiolipoma, histiocitoma fibroso aneurismático (Figuras 3 e 4) ${ }^{(28)}$.

\section{PATOGENESE DO SARCOMA DE KAPOSI}

O Sarcoma de Kaposi é uma proliferação de células endoteliais, identificada como sendo Fator VIII-positivo por imunoistoquímica ${ }^{(29)}$. Embora existam vários hiatos na compreensão da patogênese do SK, nos últimos anos os avanços foram significativos e já se advoga um modelo que inclui exposição a um agente infeccioso, outro que não o próprio HIV, modulação do crescimento do tumor por produtos genéticos do HIV e participação de citocinas na alteração da expressão e resposta da doença.

Entre os indivíduos infectados pelo HIV, a incidência de SK, predominantemente entre homens de comportamento homo/bissexual, há muito tempo sugeria que um cofator sexualmente transmitido, em associação a infecção prévia pelo HIV, fosse responsável pelo desenvolvimento do Sarcoma de Kaposi ${ }^{(11,16)}$. Em 1994 esse cofator veio a ser descoberto por Chang et al., que relataram a presença de

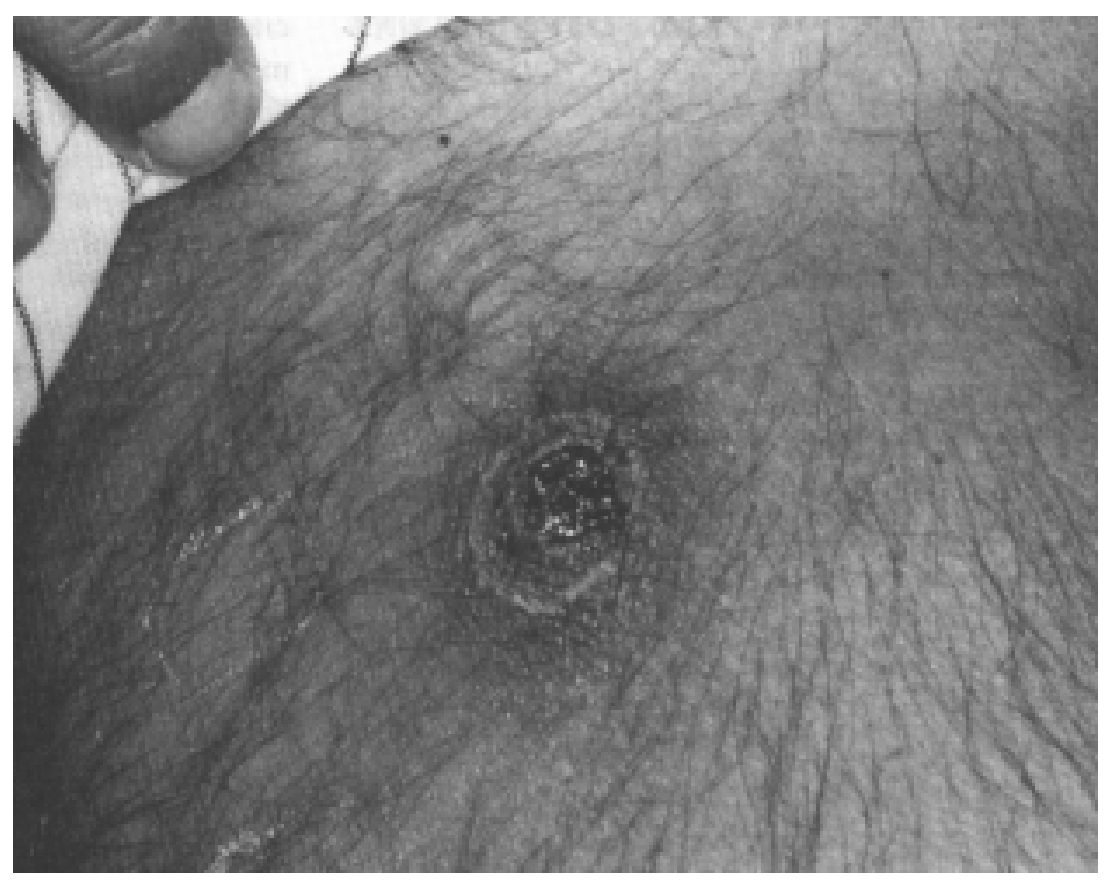

Figura 3: Lesão cutânea característica de angiomatose bacilar em paciente HIV+. Apesar de distinta neste caso, algumas vezes estas lesões são confundidas com as do Sarcoma de Kaposi.

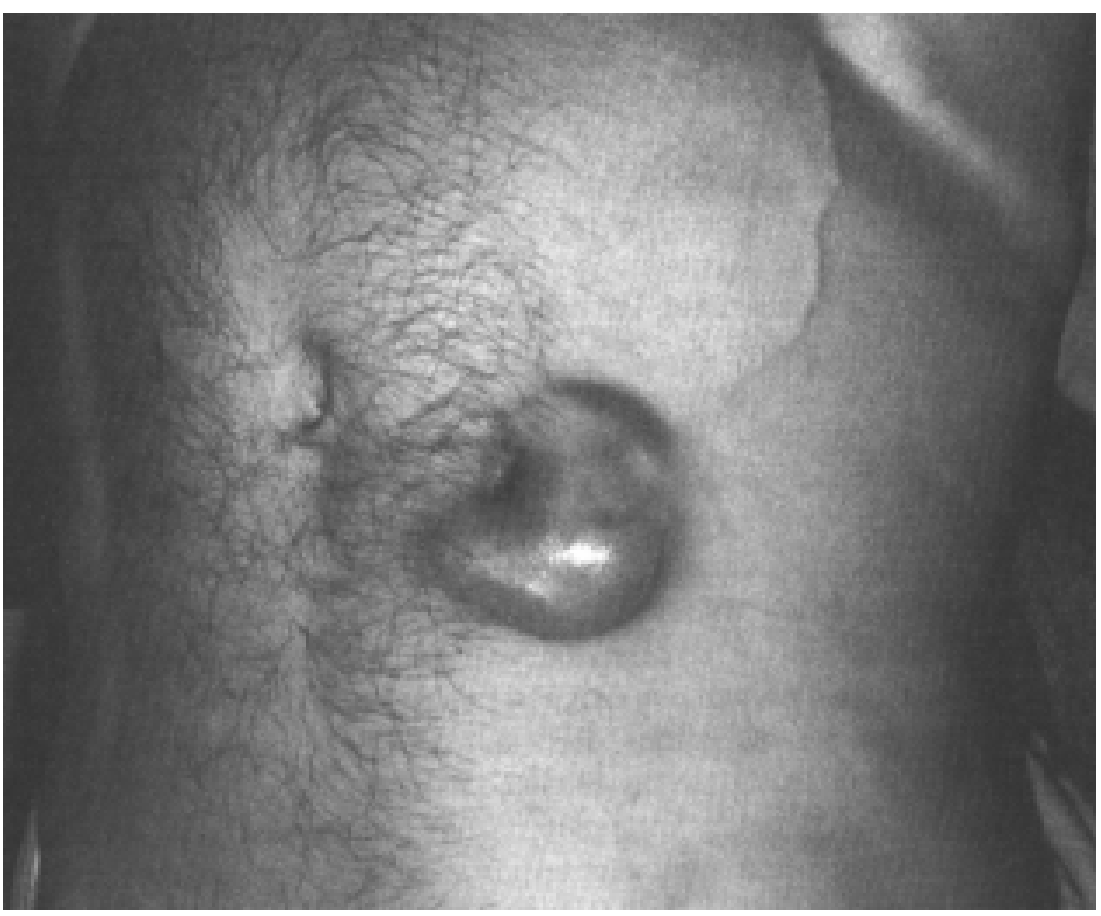

Figura 4: Linforma cutâneo em paciente HIV+. Nas fases iniciais, esta patologia pode ser confundida com o Sarcoma de Kaposi. 
uma seqüência de DNA muito parecida com a existente nos vírus da família herpes, em mais de $90 \%$ das lesões de SK em indivíduos com SIDA ${ }^{(30,31)}$. Este vírus é hoje conhecido como herpesvírus humano, tipo 8 (HVH 8) e evidências recentes sugerem que o mesmo seja sexualmente transmitido e relacionado ao grau de atividade sexual ${ }^{(11)}$. O HVH 8 foi demonstrado também em lesões de SK de várias regiões do mundo, em ambos, pacientes infectados e não infectados pelo $\mathrm{HIV}^{(32,33)}$. Além do mais, em pacientes HIV-positivos sem SK, a presença de $\mathrm{HVH}$ 8, em células mononucleares do sangue periférico, previu o aparecimento de $\mathrm{SK}^{(34)}$, e a maioria dos pacientes desenvolveram uma resposta sorológica contra o HVH 8 meses antes do diagnóstico clínico de $\mathrm{SK}^{(35)}$. Estudos epidemiológicos recentes fortaleceram a hipótese de que a infecção pelo HVH 8 precede o início do $\mathrm{SK}^{(11)}$. O mecanismo pelo qual o HVH 8 causa proliferação das células endoteliais não foi ainda esclarecido. Sabe-se que o HVH 8 apresenta um tropismo por linfócitos B CD19+, mas não está claro se o mesmo infecta células endoteliais, pois o vírus não pode ser detectado em culturas in vitro de células derivadas de $\mathrm{SK}^{(36)}$. Desta forma, enquanto o desenvolvimento inicial do SK parece resultar da infecção pelo HVH 8 em pacientes imunossuprimidos, a replicação continuada das células de SK parece ser resultado de outros fatores.

Sem dúvida, a infecção pelo HIV não é um prérequisito para o desenvolvimento do SK já que estudos moleculares não conseguiram detectar esse vírus no tecido neoplásico, o que torna improvável que o HIV desempenhe um papel oncogênico direto na etiologia do $\mathrm{SK}^{(37)}$. Entretanto, uma função mais indireta do HIV, alterando a história natural do SK, é sugerida em algumas observações. Camundongos transgênicos, possuindo o gene de transativação do HIV (gene tat) desenvolveram, transitoriamente, lesões angiogênicas semelhantes ao SK; o produto desse gene (proteína Tat) é liberado sob uma forma biologicamente ativa pelos linfócitos CD4 e monócitos infectados pelo $\mathrm{HIV}^{(38)}$. A proteína Tat, extracelular liga-se às proteínas de aderência, expressas de forma acentuada nas células fusiformes, derivadas do SK, estimulando a proliferação destas células e induzindoas a produzirem citocinas inflamatórias que estimulam a proliferação e a angiogênese por meio de alças autócrinas e parácrinas ${ }^{(39)}$. O HIV também contribui de forma mais geral para o desenvolvimento e progressão do SK, em virtude da depleção dos linfócitos CD4, acarretando uma depressão dos mecanismos imunológicos e, mais especificamente, estimulando a produção excessiva de linfocinas e monocinas (citocinas) angiogênicas, cujos níveis estão aumentados nos pacientes com infecção progressiva pelo HIV e aumentam ainda mais durante as infecções oportunistas agudas $^{(40,41)}$.

As citocinas e outros fatores de crescimento desempenham papel fundamental, estimulando o desenvolvimento e mantendo a progressão do SK in vivo. Citocinas, como interleucina-1 (IL-1), IL-6, FNT e oncostatin-M, são substâncias sabidamente envolvidas no processo de proliferação das células do $\mathrm{SK}^{(41,42)}$. As próprias células fusiformes, derivadas do SK, também produzem grande variedade de citocinas e fatores de crescimento capazes de estimular o desenvolvimento do SK. Dentre eles, estão vários tipos de fatores de crescimento dos fibroblastos ligados à heparina, fator de crescimento derivado das plaquetas, fator de crescimento do endotélio vascular, fator beta, transformador do crescimento, IL-1, IL-6 e fator estimulador das colônias de granulócitos e macrófagos; todos esses fatores são capazes de estimular a angiogênese, que é uma das características principais das lesões do $\mathrm{SK}^{(43)}$. Alguns estudos demonstraram ainda que as células normais de origem endotelial, que são ativadas, de início, pelos fatores de crescimento dos fibroblastos e citocinas liberadas pelos linfócitos $\mathrm{T}$, infectados pelo retrovírus, tornam-se sensíveis aos efeitos estimuladores da proteína tat sobre a proliferação, migração celular e diferenciação angiogênica ${ }^{(44)}$.

Em conclusão, apesar do conhecimento limitado sobre a patogênese do SK, avanços significativos foram feitos. Dados sugerem que infecção prévia pelo HVH 8, sexualmente transmitido, a proteína Tat, liberada pelos linfócitos CD4, infectados pelo HIV, e fatores de crescimento e citocinas atuam conjuntamente, induzindo a proliferação das células fusiformes do SK. Com base em tais evidências, especula-se que agentes anti-herpes, anti-retrovirais e imunoestimulatórios possam ser úteis no manejo do SK. Na verdade, análises retrospectivas demonstraram que tratamento prévio com Foscarnet e Ganciclovir, mas não com Acyclovir, pode possivelmente diminuir o risco de desenvolvimento de $\mathrm{SK}^{(45,46)}$. Além disso, a prática de sexo seguro, há muito recomendada para prevenção da SIDA, aplica-se, também, à prevenção do SK, diminuindo o risco de transmissão não só do HIV, mas agora também do HVH $8^{(11)}$. 


\section{TRATAMENTO}

Apesar de avanços cada vez maiores na compreensão dos mais variados aspectos do SK, não há, na atualidade, um tratamento único, eficaz e, nem muito menos, um consenso sobre a abordagem terapêutica desta doença em indivíduos com SIDA. A escolha de um tratamento deve ser individualizada e levar em consideração vários fatores como: gravidade do caso, extensão e localização das lesões, rapidez de progressão, grau de comprometimento imune, efeitos colaterais dos medicamentos e até questões estéticas. Os objetivos terapêuticos para cada paciente também podem ser diferentes. Abordagens diferentes podem ser usadas mesmo para pacientes com apresentações semelhantes da doença.

A Tabela III ilustra algumas situações clínicas e quais as possíveis opções de tratamento. Devemos notar que, para cada situação clínica, há mais de uma opção de tratamento, e, às vezes, opta-se até por não tratar. Isso denota as incertezas e dificuldades encontradas no manejo dessa patologia. A tabela é apenas um sumário de opções de tratamento, mas o que vai nortear a escolha será o estado clínico do paciente, o bom senso da equipe médica e a experiência do serviço no tratamento do SK/SIDA. As abordagens terapêuticas do SK podem ser divididas, basicamente, em locais e sistêmicas.

\section{TRATAMENTO LOCAL}

A radioterapia sempre foi a primeira opção para tratamento do SK localizado, antes do aparecimento do SK/SIDA, com excelentes resultados ${ }^{(47)}$. É atualmente o tratamento local preferido para indivíduos com SIDA e lesões de SK cutâneas e/ou orais, pouco numerosas e sem envolvimento visceral ${ }^{(48)}$. A mucosite é uma complicação freqüente para pacientes que recebem radiação para tratar lesões em orofaringe, portanto deve-se indicar a radioterapia apenas para lesões orais sintomáticas. Linfadenopatia dolorosa, edema de pênis e extremidades são outras situações em que estaria indicada a radioterapia. Em pacientes com um número grande de lesões, a radioterapia pode ser aplicada apenas em lesões com localização inaceitável cosmeticamente ou que resultem em sintomas como dor. Lesões tratadas com sucesso e que recidivaram podem responder a nova tentativa com radioterapia $^{(19)}$. Terapia com laser e crioterapia são formas novas e efetivas de tratamento, mas não há, ainda, estudos comparativos em relação a radioterapia. A crioterapia com nitrogênio líquido pode ser usada através de spray manual, ou haste com algodão. Os melhores resultados foram obtidos com uso de ciclos de crioterapia de trinta (30) segundos (dez (10) a vinte (20) segundos para lesão macular e trinta (30) a sessenta (60) segundos para as papulares), com dois

\begin{tabular}{|c|c|c|}
\hline "Status" do SK/SIDA & "Status" da infecção HIV & Opções de tratamento \\
\hline $\begin{array}{l}\text { Lesão cutânea pequena, número } \\
\text { menor que } 25 \text { áreas não } \\
\text { expostas }\end{array}$ & $\begin{array}{l}\text { CD4 < } 200 \mathrm{cel} / \mathrm{mm}^{3} ; \text { presença de } \\
\text { sintomas B; presença de infecção } \\
\text { oportunista. } \\
\text { CD4 > } 200 \text { cel } / \mathrm{mm}^{3} \text {; ausência de } \\
\text { sintomas B; ausência de infecção } \\
\text { oportunista. }\end{array}$ & $\begin{array}{l}\text { Não tratar } \\
\text { Tratamento local } \\
\text { Interferon } \alpha+\text { AZT } \\
\text { Vincristina ou Vimblastina } \\
\text { Não tratar } \\
\text { Radioterapia } \\
\text { Tratamento local } \\
\text { Interferon } \alpha\end{array}$ \\
\hline $\begin{array}{l}\text { Lesão cosmeticamente } \\
\text { inaceitável }\end{array}$ & Qualquer & $\begin{array}{l}\text { Radioterapia } \\
\text { Tratamento local }\end{array}$ \\
\hline $\begin{array}{l}\text { Lesão extensa do SK, e/ ou } \\
\text { doença visceral assintomática }\end{array}$ & $\begin{array}{l}\text { CD4 < } 200 \mathrm{cel} / \mathrm{mm}^{3} ; \text { presença de } \\
\text { sintomas B; presença de infecção } \\
\text { oportunista. } \\
\text { CD4 > } 200 \text { cel. } / \mathrm{mm}^{3} ; \text { ausência de } \\
\text { sintomas B; ausência de infecção } \\
\text { oportunista. }\end{array}$ & $\begin{array}{l}\text { Monoquimioterapioa } \\
\text { Poliquimioterapia } \\
\text { Interferon } \alpha+\mathrm{AZT} \\
\text { Monoquimioterapia } \\
\text { Poliquimioterapia } \\
\text { Interferon } \alpha\end{array}$ \\
\hline Lesão dolorosa localizada & Qualquer & Radioterapia \\
\hline Lesão com edema associado & Qualquer & $\begin{array}{l}\text { Monoquimioterapia } \\
\text { Poliquimioterapia } \\
\text { Radioterapia }\end{array}$ \\
\hline SK/SIDA visceral sintomático & Qualquer & Poliquimioterapia \\
\hline
\end{tabular}


ciclos de tratamento, repetidos com intervalos de três (03) semanas, e com média de três (03) aplicações por lesão. As lesões maculares e papulares com menos de $1 \mathrm{~cm}$ de diâmetro são as que apresentam melhores resultados, com até $85 \%$ de resposta total e parcial. Efeitos adversos mais comuns são dor e, raramente, infecção secundária ${ }^{(49)}$. O laser foi usado com sucesso para lesões da cavidade oral, mas, para lesões cutâneas, o uso do laser está associado a alto índice de recorrência ${ }^{(19)}$.

Injeção local de vincristina tem sido recomendada para pacientes com poucas lesões cutâneas. Mostrou-se mais efetiva que a crioterapia para lesões papulares e nodulares maiores que $1 \mathrm{~cm}$ de diâmetro, bem como para lesões sintomáticas na cavidade oral. Uma resposta parcial foi observada em mais de $90 \%$ das lesões e poucos efeitos colaterais foram observados. Uma desvantagem é que, geralmente, há hiperpigmentação residual. Além disso, alopecia, dor e até necrose tecidual local podem ocorrer se a droga não for precisamente injetada na lesão. Deve-se evitar a injeção do quimioterápico em áreas próximas a trajeto de nervos periféricos. As injeções repetitivas são desconfortáveis para os pacientes. A chance de recorrência em seis (06) meses é de aproximadamente $40 \%{ }^{(50)}$. Injeção local de Interferon-alfa (INF-alfa) tem sido reportada, levando à regressão do SK cutâneo, porém, essa conduta deve ser revista, pois estudo recente não mostrou diferença de resposta, quando comparadas injeções intralesionais de INF-alfa e solução salina isotônica ${ }^{(51)}$. Remoção cirúrgica também não deve ser recomendada, já que o tumor recidiva na cicatriz em uma proporção significativa de pacientes ${ }^{(19)}$.

\section{TRATAMENTO SISTÊMICO}

Avaliação da resposta ao tratamento sistêmico para SK é, geralmente, dividida em resposta completa (RC), resposta parcial (RP) e não resposta ou progressão da doença. Resposta parcial é definida como diminuição de $50 \%$ ou mais no tamanho, número ou nodularidade das lesões, por pelo menos quatro (04) semanas. A progressão da doença é definida como aumento de mais de $25 \%$ no tamanho, número ou nodularidade das lesões, na vigência ou não de tratamento. Pacientes que não se encaixam nesses grupos são classificados como tendo doença estável ${ }^{(27)}$.

Pacientes ainda sem terapia anti-retroviral, devem começá-la plenamente quando do diagnóstico de SK. Essa recomendação é baseada em evidências antigas, que mostraram que o aparecimento do SK está relacionado a imunodeficiência ${ }^{(6)}$ e a recuperação, mesmo parcial, do estado imunológico de pacientes portadores ou não de infecção pelo HIV trouxe regressão parcial ou total das lesões de $\mathrm{SK}^{(7,52)}$. Nos últimos anos, com o advento dos inibidores de protease e sua associação com drogas antigas e de outros grupos, vem sendo possível o emprego de uma terapia anti-retroviral combinada e altamente ativa, conseguindo-se uma restauração da imunidade de forma bem mais importante e duradoura, ainda que parcial. Esse avanço vem alterando drasticamente a evolução dos pacientes portadores da infecção pelo HIV e suas complicações. Em relação ao SK, têm se observado vários casos de regressão completa das lesões de SK, tanto em pele como em vísceras, com a terapia antiretroviral, altamente ativa ${ }^{(53,54)}$.

Interferon-alfa (INF-alfa) sistêmico, isoladamente ou em combinação com Zidovudina, tem se mostrado eficaz no tratamento do SK, com respostas parcial ou completa em $30-70 \%$ dos casos $^{(55)}$. O INFalfa é um agente imunomodulador, que teria ação no SK/SIDA pelo seu efeito antiproliferativo, além de ação antiviral e imunoestimulante, o que teoricamente seria vantajoso, quando comparado com agentes citotóxicos. O mecanismo de ação do INF-alfa não é conhecido exatamente, mas acredita-se ser a ação antiproliferativa, a mais importante, visto que nenhuma melhora nos parâmetros imunológicos foi descrita nos pacientes em uso da droga ${ }^{(56)}$. As melhores taxas de resposta foram observadas em indivíduos com CD4 acima de $200 / \mathrm{mm}^{3}$, o que representa uma limitação do uso do INF-alfa, já que apenas $5 \%$ dos pacientes têm uma contagem de CD4 acima dessa faixa, no momento do diagnóstico de $\mathrm{SK}^{(19)}$. Outro aspecto importante a ser observado, quando da escolha dessa terapêutica, é a incidência elevada de efeitos colaterais relacionados ao uso de INF-alfa (febre, calafrios, mal-estar), às vezes severos. A dose deve, no início, ser baixa, no intuito de minimizar esses efeitos colaterais.

\section{QUIMIOTERAPIA SISTÊMICA}

$\mathrm{O}$ fato de o paciente com SK/SIDA ser um indivíduo com uma imunodeficiência de base, causou certa relutância quanto ao uso de esquemas terapêuticos com drogas citotóxicas, pelo temor de se agravar a situação do paciente. Por isso, inicialmente, evitou-se o uso de drogas combinadas, e, nas doses usuais, dáse preferência à monoterapia ou à associação de fármacos com doses reduzidas, conforme instruções do Instituto Nacional do Câncer, Norte Americano ${ }^{(57)}$. 
Os esquemas terapêuticos serão discutidos adiante e estão resumidos na Tabela IV; no entanto, é muito difícil comparar sua eficácia, pois os estudos feitos não usam os mesmos critérios de estadiamento, podendo, então, termos uma excelente resposta com uma monoterapia para pacientes com SK/SIDA numa fase mais inicial e com bom prognóstico, e péssimos resultados se usarmos associação de quimioterápicos para os casos de doença mais avançados, que, geralmente, não respondem à monoquimioterapia. Embora a maioria dos esquemas apresentem boas taxas de resposta, todos têm uma limitação importante, que é a alta taxa de recidiva da doença. Dentre os agentes quimioterápicos de uso sistêmico, os mais extensivamentes estudados têm sido os alcalóides da vinca (Vincristina e Vimblastina), a bleomicina e as antraciclinas (Daunorubicina e Doxorubicina) ${ }^{(19)}$.

Monoterapia com Vincristina tem resultado em resposta parcial (RP), em aproximadamente $60 \%$ dos casos, com duração média da resposta de quatro (04) meses; não há descrição de resposta completa. $\mathrm{O}$ esquema proposto é de $2 \mathrm{mg}$ de Vincristina por semana, endovenoso em bolus por duas (02) a cinco (05) semanas na fase de ataque, seguido da manutenção com 1 a $2 \mathrm{mg}$ a cada quinze (15) dias, continuamente, até que haja estabilização das lesões por um período de quatro (04) semanas, cura total, falha terapêutica ou efeitos colaterais que contra-indiquem a manutenção do tratamento ${ }^{(58)}$. Já o uso isolado de Vimblastina re- sulta em RP, que pode variar de $26-65 \%$ dos casos, com duração média da resposta de semanas a meses. O esquema proposto é de 4 a $8 \mathrm{mg} / \mathrm{semana}$, continuamente. Geralmente, inicia-se com dose de $4 \mathrm{mg}$ e, gradativamente, deve-se aumentar a dose para $6 \mathrm{mg}$, se o número de leucócitos não cair abaixo de $2500 / \mathrm{mm}^{3}$ ${ }^{(59,60)}$. Os principais efeitos colaterais da Vincristina e da Vimblastina são, respectivamente, neuropatia periférica ( $20 \%$ dos casos) e mielossupressão. A mielossupressão causada pela Vimblastina merece especial atenção e pode ser problemática nos pacientes com SIDA, que já têm, sabidamente, uma medula óssea com reserva pequena, tanto pela ação direta do HIV como pelo uso de outros agentes mielossupressores, como a Zidovudina e as Sulfas. Uma alternativa é o uso concomitante de substâncias estimuladoras da mielopoiese. O risco de desenvolver neuropatia periférica também pode aumentar nos pacientes que fazem uso concomitante de Vincristina e Didanosina ou Zalcitabina $^{(19)}$. Com o objetivo de abrandar esses efeitos colaterais, tem sido proposto o uso alternado dessas drogas, sendo observadas melhor tolerância e taxa de resposta intermediária (RP/RC em $43 \%$ dos casos). Estudo feito com vinte e um (21) pacientes usou o seguinte esquema: $2 \mathrm{mg}$ de Vincristina em bolus $\mathrm{EV}$, a cada quinze (15) dias, intercalado com $0,1 \mathrm{mg} / \mathrm{kg}$ de Vimblastina (máximo de $8 \mathrm{mg}$ ), a cada quinze (15) dias, também EV e em bolus, de modo que, a cada sete (07) dias, o paciente receberia uma das drogas.

\begin{tabular}{|c|c|c|c|c|}
\hline Drogas & Dose e via de adm. & Freqüência de administração & Efeitos colaterais & $\begin{array}{l}\% \text { de } \\
\text { resposta }\end{array}$ \\
\hline Vincristina & $2 \mathrm{mg}(\mathrm{EV})$ & $\begin{array}{l}\text { Ataque: } 7 \text { / 7dias, por } 2 \text { a } 5 \\
\text { semanas } \\
\text { Manutenção: } 15 \text { / } 15 \text { dias }\end{array}$ & Neuropatia & $61 \%$ \\
\hline Vimblastina & 4 a $8 \mathrm{mg}$ (EV) & $7 / 7$ dias & Mielotoxicidade & $26 \%$ \\
\hline $\begin{array}{l}\text { Vincristina } \\
\text { Alternada c/ } \\
\text { Vimblastina }\end{array}$ & $\begin{array}{l}2 \mathrm{mg} \\
(\mathrm{EV}) 4 \mathrm{a} 8 \mathrm{mg}\end{array}$ & 1 droga a cada 7 dias & $\begin{array}{l}\text { Neuropatia } \\
\text { e } \\
\text { Mielotoxicidade }\end{array}$ & $43 \%$ \\
\hline Doxorubicina & $20 \mathrm{mg} / \mathrm{m}^{2} / \mathrm{SC}(\mathrm{EV})$ & $15 / 15$ dias & Mielotoxicidade & $48 \%$ \\
\hline $\begin{array}{l}\text { Daunorubicina } \\
\text { Lipossomal }\end{array}$ & $40 \mathrm{mg} / \mathrm{m}^{2} / \mathrm{SC}$ & $15 / 15$ dias & Mielotoxicidade & 25 a $40 \%$ \\
\hline $\begin{array}{l}\text { Doxorubicina } \\
\text { Bleomicina } \\
\text { Vincristina }\end{array}$ & $\begin{array}{l}10-20 \mathrm{mg} / \mathrm{m}^{2} / \mathrm{SC} \\
15 \mathrm{mg} / \mathrm{m}^{2} / \mathrm{SC}(\mathrm{EV}) \\
2 \mathrm{mg}\end{array}$ & $15 / 15$ dias & $\begin{array}{l}\text { Mielotoxicidade } \\
\text { "Rash" cutâneo e } \\
\text { fibrose pulmonar } \\
\text { Neuropatia }\end{array}$ & 80 a $90 \%$ \\
\hline Interferon- $\alpha$ & $\begin{array}{l}20 \times 10^{6} \mathrm{UI} / \mathrm{m}^{2} / \mathrm{SC} \\
(\mathrm{IM})\end{array}$ & $\begin{array}{l}5 \text { a } 7 \text { vezes/ semana (4 sem.) } \\
\text { seguido de } 3 \text { vezes/sem ( } 8 \text { sem.) }\end{array}$ & $\begin{array}{l}\text { Calafrios } \\
\text { Febre } \\
\text { Mal-estar }\end{array}$ & 20 a $50 \%$ \\
\hline
\end{tabular}

OBS: O tratamento, em geral, é suspenso após quatro (4) semanas de estabilização da doença, se houver cura, recidiva da doença na vigência da terapia, ou efeito colateral que contra-indique a manutenção da droga.

EV: endovenoso; VO: via oral; IM: intramuscular; SC: superfície corporal. 
Dos vinte e um (21) pacientes, apenas um (01) obteve resposta completa (5\%), oito (08) responderam parcialmente $(38 \%)$ e sete (07) tiveram sua doença estabilizada $(33 \%)^{(61)}$.

A Bleomicina também tem sido usada como monoterapia, mas seus melhores resultados foram observados com o uso combinado com a Vincristina (RP/ RC em $72 \%$ dos casos) ${ }^{(62)}$. Essa droga tem ação mielossupressora mínima e seu efeito colateral mais temido é o desenvolvimento de fibrose pulmonar, que ocorre apenas em doses cumulativas muito superiores às usadas no tratamento do SK. Portanto, pelas características dos agentes expostos acima, a combinação de Bleomicina com Vincristina (BV) parece estar associada com melhor resposta e menor mielossupressão, e é uma das opções terapêuticas de primeira linha.

$\mathrm{O}$ uso de antraciclinas em combinação com outros quimioterápicos tem sido empregado há mais de dez (10) anos, no tratamento do SK, em pacientes com SIDA. Esquema empregando Doxorubicina associada a Bleomicina e Vimblastina (DBV), em ciclos a cada quatro (04) semanas, foi associado a resposta mais satisfatória (RP/RC em $84 \%$ dos pacientes) e mais duradoura (média de oito (08) meses) ${ }^{(63)}$. A grande desvantagem desse esquema é a mielossupressão severa e prolongada que se instala, associada a uma maior incidência de infecções oportunistas. Isso pode ser abrandado com o uso de Vincristina em substituição a Vimblastina e com doses menores de Doxorubicina, diminuindo a chance de suspensão de anti-retrovirais, como a Zidovudina ${ }^{(62,64)}$. Os efeitos adversos, observados com mais frequiência, foram náuseas, vômitos, queda de cabelo, neuropatia periférica sensorial (Vincristina) e "rash" cutâneo, associado a Bleomicina, além da granulocitopenia. É difícil avaliar o risco de se desenvolverem infecções oportunistas, devido à dificuldade de se fazerem estudos com grupos de controle. Durante o tratamento com DBV, também se deve evitar o uso de AZT, Ganciclovir, ou qualquer medicação mielossupressora. $\mathrm{O}$ uso concomitante de fator de estímulo de crescimento de colônia de granulócitos e macrófagos tem sido usado com bons resultados ${ }^{(65)}$. Recomenda-se fazer uso de profilaxia para pneumocistose. Doxorubicina, como monoterapia, foi significativamente menos eficaz que os esquemas de associação (DBV), não sendo recomendada ${ }^{(62)}$.

Em recente abordagem, têm-se usado antraciclinas encapsuladas em lipossomos, como monoterapia. Essas formas lipossomais, por serem liberadas mais lentamente e atingirem concentrações maiores dentro das células tumorais, são mais eficazes, melhor toleradas e menos mielotóxicas ${ }^{(66)}$. Apesar da pouca experiência acumulada, estudo recente, randomizado, envolvendo duzentos e setenta e sete (277) pacientes com SK avançado, avaliou, comparativamente, o uso da Daunorubicina Lipossomal $\left(40 \mathrm{mg} / \mathrm{m}^{2}\right.$ a cada duas (02) semanas) como monoterapia e o esquema DBV, observando-se resposta semelhante nos dois grupos. Neuropatia periférica e alopécia foram menos freqüentes nos pacientes tratados com Daunorubicina Lipossomal. Nenhuma diferença, contudo, foi observada em relação à sobrevida, incidência de neutropenia e risco de desenvolvimento de infecções oportunistas ${ }^{(67)}$. A Doxorubicina Lipossomal também se mostrou eficaz no tratamento de SK, especialmente em pacientes que já haviam sido tratados com outros esquemas tradicionais e não haviam obtido resposta, ou apresentaram recidiva da doença ${ }^{(68)}$.

Outras drogas para tratamento sistêmico do SK estão sendo investigadas e testadas. Em estudo recente, avaliando componentes capazes de controlar o crescimento das células do SK/SIDA foi testada uma substância produzida a partir da parede celular da bactéria Arthrobacter sp, que foi denominada peptidoglicano polissacarídeo sulfatado, ou SP-PG, sigla em inglês para "Sulfated polysaccharide-peptidoglycan". O SP-PG provou ser capaz de inibir o crescimento das células fusiformes do SK/SIDA in vitro e in vivo, em experimentos com camundongos do tipo nude, em concentrações não tóxicas ${ }^{(69)}$. Recentemente, observou-se que a gonadotrofina coriônica humana causa inibição de crescimento de células de SK in vitro, e duas (02) mulheres com SIDA e SK tiveram remissão completa durante a gravide ${ }^{(70)}$. Alguns relatos de casos sugeriram que antivirais ativos contra a família Herpesviridae, tais como o Foscarnet e o Cidofovir podem causar regressão no tamanho das lesões de SK e estudos controlados estão em andamento ${ }^{(71,72)}$. Outras opções terapêuticas, em estudo para controle do SK/SIDA, são: derivados sintéticos da heparina ${ }^{(73)}$, análogos da vitamina $\mathrm{D} 3^{(74)} \mathrm{e}$ fator 4 recombinante de plaqueta humana ${ }^{(75)}$. Uma nova droga, já avaliada no SK/SIDA, denominada Paclitaxel tem mostrado resultados animadores com taxa de resposta de até $65 \%{ }^{(76)}$. Recentemente, após observação de que a subunidade beta da gonadotrofina coriônica humana (HCG) tem ação antitumoral no SK, estudos com uso dessa substância já estão sendo realizados com seu uso por injeção sistêmica, local e subcutânea em pacientes com doença avançada pelo HIV, nos quais a quimio e a radioterapia para o SK foram contra-indicadas ou ineficazes. Apesar de poucos efeitos colaterais, o uso do beta-HCG proporcionou resposta parcial e estabilização das lesões em $50 \%$ dos casos estudados ${ }^{(77)}$. 
A gravidade da infecção subjacente pelo HIV e das suas complicações associadas também deve ser levada em consideração. Problemas específicos (neuropatia periférica, disfunção cardíaca ou pulmonar, doença hepática grave) podem eliminar algumas opções terapêuticas. Quando a expectativa de vida é extremamente curta devido às outras complicações relacionadas ao HIV, a paliação dos sintomas locais deve nortear o tratamento. Entretanto, a simples contagem de CD4 baixa não deve ser justificativa para se evitar quimioterapia sistêmica, se esta estiver indicada. Além disso, medidas de sustentação adequadas, esquemas profiláticos e terapia anti-retroviral associados ao tratamento do SK têm diminuido o risco de infecções oportunistas. Dessa forma, a profilaxia, o diagnóstico e o tratamento imediatos das infecções oportunistas são fundamentais como parte da estratégia terapêutica global para o SK. Essas infecções, além de estimularem a progressão do SK, podem causar retardos no tratamento dessa neoplasia. O uso concomitante de uma grande variedade de medicamentos pelos pacientes com SIDA traz também preocupações quanto ao risco potencial de interações medicamentosas. Pacientes tratados com intervenções sistêmicas devem ser monitorizados e tratados para mielossupressão e precisam receber atenção especial em relação ao estado nutricional e controle da dor.

\section{CONCLUSÃO}

Uma discussão aberta entre o médico e o paciente que descreva os riscos e benefícios dos vários tratamentos, a história natural variável do SK, os conceitos gerais sobre a patogenia da doença e o prognóstico e objetivo a longo prazo é extremamente útil para ajudar o paciente e seu médico a escolherem uma abordagem terapêutica adequada para o SK. Nunca se deve perder de vista o objetivo do tratamento da doença para cada paciente. Até o momento, não há terapia curativa para o SK/SIDA e este não deve ser o objetivo. Só raramente a progressão do tumor leva ao óbito, e a maioria dos pacientes morre devido a complicações não relacionadas ao SK, como infecções oportunistas. Embora tenha havido progressos no tratamento da infecção pelo HIV e suas complicações, contribuindo para o aumento da sobrevida dos pacientes HIV-positivos, não existem ainda estudos indicando que os tratamentos antineoplásicos específicos prolonguem a sobrevida dos pacientes com SK. Provavelmente, outros fatores além do SK são importantes determinantes da sobrevida e todos os pacientes devem receber terapia anti-retroviral, combinada, altamente ativa. Por fim, de maneira geral e até o momento, o que se deve buscar é o controle da doença e a paliação eficaz dos sintomas.

FONSECA BAL; BOLLELA VR \& NETO RJP. Kaposi's Sarcoma and acquired immunodeficiency syndrome: characteristics of this association including new concepts on pathogenesis and treatment. Medicina, Ribeirão Preto, 32: 26-39, jan./march 1999.

ABSTRACT: In early 80 's, the acquired immunodeficiency syndrome was initially recognized from the outbreak of Kaposi's sarcoma and Pneumocystis carinii pneumonia among young, previously healthy homosexual men. Kaposi's sarcoma is the most frequent neoplasm associated with human immunodeficiency virus (HIV) infection. Although Kaposi's sarcoma pathogenesis is not clear at all, the disease has been associated with the presence of a sexual transmitted herpes virus. This paper intends to review and update some topics about HIV/Kaposi's sarcoma pathogenesis and therapeutic aspects.

UNITERMS: Acquired Immunodeficiency Syndrome. Sarcoma, Kaposi's. Pathogenesis. Treatment.

\section{REFERÊNCIAS BIBLIOGRÁFICAS}

1 - KAPOSI M. Idiopathic pigmented sarcoma of skin. Cancer $\mathbf{J}$ Clin 32: 342-347, 1982.

2 - ZURRIDA S et al. Classic Kaposi's sarcoma: a review of 90 cases. J Dermatol 19: 548-552, 1992.
3 - DIGIOVANNA JJ \& SAFAI B. Retrospective study of 90 cases with particular emphasis on the familial occurrence, ethnic background and prevalence of other diseases. Am J Med 71:779783, 1981.

4 - DAVIES JNP \& LOTHE R. Kaposi's sarcoma in African children. Acta Un Int Cancr 18:394-399, 1962. 
5 - GANGE RW \& WILSON JE. Kaposi's sarcoma and imunosuppressive therapy. Clin Exp Dermatol 3: 135-146, 1978.

6 - FRIENDMAN-KIEN A et al. Kaposi's sarcoma and Pneumocystis pneumonia among homosexual men-New York and California. MMWR Morb Mortal Wkly Rep 30, 305-308, 1981.

7 - LUNDGREN JD et al. Changing patterns of Kaposi's sarcoma in Danish AIDS patients with complete follow-up. Am J Epidemiol 141: 652-658, 1995.

8 - HERMANS $P$ et al. Epidemiology of AIDS-related Kaposi's sarcoma in Europe over 10 years. AIDS 10: 911-917, 1996.

9 - LIFSON AR et al. Kaposi's sarcoma in a cohort of homosexual and bisexual men. Am J Epidemiol 131: 221-231, 1990.

10 - ELFORD $\mathrm{J}$ et al. Kaposi's sarcoma as a sexually transmissible infection: an analysis of Australian AIDS surveillance data. AIDS 7: 1667-1671, 1993.

11 - MARTIN JN et al. Sexual transmission and the natural history of human herpesvirus 8 infection. N Engl J Med 338: 948-954, 1998.

12 - FARTHING CF et al. Sarcoma de Kaposi. In: FARTHING CF et al., eds. Atlas colorido de AIDS. Artes Médicas, São Paulo, p.59-72, 1989.

13 - ROTHMAN S. Remarks on sex, age and racial distribution of Kaposi's sarcoma and on possible pathogenic factors. Acta Un Int Cancr 18: 326-329, 1962.

14 - CENTERS FOR DISEASE CONTROL Task Force on Kaposi's sarcoma and opportunistic infections. Epidemiologic aspects of the current outbreak of Kaposi's sarcoma and opportunistic infections. N Engl J Med 306: 248-252, 1982.

15 - MINISTÉRIO DA SAÚDE. Coordenação Nacional de Doenças Sexualmente Transmissíveis e AIDS. Bol Epidemiol AIDS, Ano X, n. 4, 1997.

16 - BERAL V et al. Kaposi's sarcoma among persons with AIDS: a sexually transmitted infection? Lancet 335: 123-128, 1990.

17 - FISCHL MA et al. The efficacy of azidothymidine (AZT) in the treatment of patients with AIDS and AIDS-related complex: a double-blind, placebo-controlled trial. N Engl J Med 317: 185-191, 1987

18 - DIVISÃO DE VIGILÂNCIA EPIDEMIOLÓGICA DE RIBEIRÃOPRETO. Ficha epidemiológica. Distribuição dos Casos de AIDS diagnosticados na DIR XVIII, no período de 1984 a 1997. Ribeirão Preto, 1998.

19 - LUNDGREN JD et al. Kaposi's sarcoma and its management in AIDS patients: recommendations from a Scandinavian group. Scand J Infect Dis 29: 3-12, 1997.

20 - FICARRA G et al. Kaposi's sarcoma of the oral cavity: A study of 134 patients with a review of the pathogenesis, epidemiology, clinical aspects and treatment. Oral Surg Oral Med Oral Pathol 66: 543-550, 1988.

21 - JANIER $M$ et al. The koebner phenomenon in AIDS-related Kaposi's sarcoma. J Am Acad Dermatol 22: 125-126, 1990.

22 - SAFAI B et al. The natural history of Kaposi's sarcoma in AIDS. Ann Intern Med 103: 744-750, 1985.

23 - FRIEDMAN SL et al. Gastrointestinal Kaposi's sarcoma in patients with AIDS. Endoscopic and autopsy findings. Gas- troenterology 89: 102-108, 1985.

24 - FREDERICK $P$ et al.Kaposi's sarcoma causing infiltrates and respiratory failure in AIDS. Ann Intern Med 102: 471-475, 1985.

25 - KRIEGEL RL. The treatment and nature history of Kaposi's sarcoma. Proc NY Acad Sci 437: 447-450, 1984

26 - SAFAI B \& SCHWARTZ J. Kaposi's sarcoma and the acquired immunodeficiency syndrome. In: DE VITA VT et al. eds. AIDS, etiology, diagnosis, treatment and prevention.3rd ed, JB Lippincott, Philadelphia, p. 209-223, 1992.

27 - KROWN S et al. Kaposi's sarcoma in the acquired immunodeficiency syndrome: a proposal for uniform evaluation, response and staging criteria. J Clin Oncol 7: 1201-1207, 1989.

28 - CHOR PJ \& SANTA CRUZ DJ. Kaposi's sarcoma: a clinicpathologic review and differential diagnosis. J Cutan Pathol 19: 6-20, 1992.

29 - GUARDA LG et al. Factor VIII in Kaposi's sarcoma. Am J Clin Pathol 76: 197-200, 1981.

30 - CHANG $Y$ et al. Identification of herpesvirus-like DNA sequences in AIDS-associated Kaposi's sarcoma. Science 266: 1865-1869, 1994.

31 - LEVY JA. A new human herpesvirus: KSHV or HHV-8? Lancet 346: 786, 1995.

32 - MOORE PS \& CHANG Y. Detection of herpes-like DNA sequences in Kaposi's sarcoma in patients with and those without HIV infection. N Engl J Med 332: 1181-1185, 1995.

33 - DUPIN N et al. Herpes-like DNA sequences in patient with Mediterranean Kaposi's sarcoma. Lancet 345: 761-762, 1995.

34 - WHITBY D et al. Detection of Kaposi's sarcoma associated herpesvirus in peripheral blood of HIV-infected individuals and progression to Kaposi's sarcoma. Lancet 346: 799-802, 1995.

35 - GAO SJ et al. Seroconversion to antibodies against Kaposi's sarcoma-associated herpesvirus-related latent nuclear antigens before the development of Kaposi's sarcoma. N Engl J Med 335: 233-241, 1996

36 - AMBROSIAC JA et al. Herpes-like sequences in HIV-infected and uninfected Kaposi's sarcoma patients. Science 268: 582583,1995

37 - BIGGAR RJ. Cancer in acquired immunodeficiency syndrome: An epidemiological assessment. Semin Oncol 17: 251-260, 1990

38 - VOGEL $\mathrm{J}$ et al. The HIV tat gene induces dermal lesions resembling Kaposi's sarcoma in transgenic mice. Nature 335: 606-611, 1988.

39 - BARILLARI G et al. The Tat protein of human immunodeficiency virus type 1: a growth factor for AIDS Kaposi's sarcoma and cytokine-activated vascular cells induces adhesion of the same cell types by using integrin receptors recognizing the RGD amino acid sequence. Proc Natl Acad Sci USA 90: 7941-7945, 1993.

40 - ROSEMBERG ZF \& FAUCI AS. Immunopathogenesis of HIV infection. FASEB J 5: 2382-2390, 1991.

41 - BARILLARI G et al. Effects of cytokines from activated immune cells on vascular cell growth and HIV-1 gene expression: implications for AIDS-Kaposi's sarcoma pathogenesis. 
J Immunol 149: 3727-3734, 1992.

42 - MILES AS et al. Oncostatin M as a potent mitogen for AIDSKaposi's sarcoma-derived cells. Science 255: 1432-1434, 1992.

43 - ENSOLI B et al. AIDS-Kaposi's sarcoma-derived cells express cytokines with autocrine and paracrine growth effects. Science 243: 223-226, 1989.

44 - FIORELLI $V$ et al. Cytokines from activated $T$ cells induce normal endothelial cells to acquire the phenotypic and functional features of AIDS-Kaposi's sarcoma spindle cells. J Clin Invest 95: 1723-1734, 1995.

45 - MOCROFT A et al. Anti-herpesvirus treatment and risk of Kaposi's sarcoma in HIV infection. AIDS 10: 1101-1105, 1996.

46 - GLESBY MJ et al. Use of antiherpes drugs and the risk of Kaposi's sarcoma: data from the Multicenter AIDS Cohort Study. J Infect Dis 173: 1477-1480, 1996.

47 - HOLECEK MJ \& HARWOOD AR. Radiotherapy of Kaposi's sarcoma. Cancer 41: 1733-1738, 1978.

48 - NOBLER MP et al. The impact of palliative irradiation on the management of patients with acquires immunodeficiency syndrome. J Clin Oncol 5: 107-112, 1987.

49 - TAPPERO JW et al. Cryotherapy for cutaneous Kaposi's sarcoma associated with acquired immune deficiency syndrome: a phase II trial. J AIDS 4: 839-846, 1991.

50 - BRAMBILLA L et al. Intralesional chemotherapy for Kaposi's sarcoma. Dermatologica 169: 150-155, 1984.

51 - DUPUY J et al. Intralesional interferon-alpha and zidovudine in epidemic Kaposi's sarcoma. J Am Acad Dermatol 28: 966-972, 1993.

52 - CONCORDE COORDINATING COMMITTEE. MRC/ANRS randomised double-blind controlled trial of immediate and deferred zidovudine in symptome-free HIV infection. Lancet 343: 871-881, 1994.

53 - NETO RJP; CASTRO G \& FONSECA BAL. Complete remission of AIDS-related Kaposi's sarcoma with highly active antiretroviral therapy. Virus Rev Res 3:115 (H-83), 1998.

54 - ABOULAFIA DM. Regression of acquired immunodeficiency syndrome-related pulmonary Kaposi's sarcoma after highly active antiretroviral therapy. Mayo Clin Proc 73: 439-443, 1998.

55 - PODZAMCZER D et al. Low-dose interferon-alpha combined with zidovudine in patients with AIDS-associated Kaposi's sarcoma. J Intern Med 233: 247-253, 1993.

56 - KROWN SE et al. Preliminary observations on the effect of recombinant leukocyte $A$ interferon in homosexual men with Kaposi's sarcoma. N Engl J Med 308: 1071-1076, 1983.

57 - DE WYS WD et al. Workshop on Kaposi's sarcoma. Meeting report. Cancer Treat Rep 66: 1387-1399, 1982.

58 - MINTZER DM et al. Treatment of Kaposi's sarcoma and trombocytopenia with vincristine in patients with the Acquired Immunodeficiency Syndrome. Ann Intern Med 102: 200202, 1985.

59 - VOLBERDING PA et al.Vinblastine therapy for Kaposi's sarcoma in the Acquired Immunodeficiency Syndrome. Ann Intern Med 103: 335-338, 1985.

60 - VOLBERDING P. Therapy of Kaposi Sarcoma in AIDS. Semin
Oncol 11: 60-67, 1984

61 - KAPLAN L et al. Treatment of Kaposi's sarcoma in Acquired Immunodeficiency Syndrome with an alternating vincristinevimblastine regimen. Cancer Treat Rep 70: 1121-1122, 1986.

62 - GILL PS et al. Systemic treatment of AIDS-related Kaposi's sarcoma: result of a randomized trial. Am J Med 90: 427433, 1991.

63 - LAUBENSTEIN LJ et al. Treatment of epidemic Kaposi's sarcoma with etoposide or a combination of doxorubicin, bleomicin, and vimblastine. J Clin Oncol 2: 1115-1120, 1984.

64 - GILL PS et al. Phase 1 AIDS Clinical Trials Group (075) study of adriamycin, bleomycin and vincristine chemoterapy with zidovudine in the treatment of AIDS-related Kaposi's sarcoma. AIDS 8: 1695-1699, 1994.

65 - DAVEY RT et al. A phase I/II trial of zidovudine, interferon a, and granulocyte-macrophage colony-stimulating factor in the treatment of human immunodeficiency virus type 1 infection. J Infect Dis 164: 43-52, 1991.

66 - GABIZONA. Selectiva tumor localization and improved therapeutic index of anthracyclines encapsulated in long-circulating liposomes. Cancer Res 52: 891-896, 1992.

67 - UTHAYAKUMAR $S$ et al. Randomized cross-over comparison of liposomal daunorubicin versus observation for early Kaposi's sarcoma. AIDS 10: 515-519, 1996.

68 - NORTHFELT BW et al. Efficacy of pegylated-liposomal doxorubicin in the treatment of AIDS-related Kaposi's sarcoma after failure of standard chemotherapy. J Clin Oncol 15: 653-659, 1997.

69 - NAKAMURA $S$ et al. Inhibition of development of Kaposi's sarcoma - related lesions by a bacterial cell-wall complex. Science 255: 1438-1440, 1992.

70 - LUNARDI-ISKANDAR $Y$ et al. Tumorigenesis and metastasis of neoplastic Kaposi's sarcoma cell line in immunodeficiency mice blocked by a human pregnancy hormone. Nature 375: 64-68, 1995.

71 - MORFELDT L \& TORSSANDER J. Long-term remission of Kaposi's sarcoma following foscarnet treatment in HIV-infected patients. Scand J Infect Dis 26: 749-752, 1994.

72 - MEDVECZKY MM et al. In vitro antiviral drug sensitivity of the Kaposi's sarcoma-associated herpesvirus. AIDS 11: 1327-1332, 1997.

73 - FOLKMAN J et al. Control of angiogenesis with synthetic heparin substitutes. Science 243: 1490-1493, 1989.

74 - OIKAWA T et al. Inhibition of angiogenesis by vitamin D3 analogues. Eur J Pharmacol 178: 247-250, 1990.

75 - MAIONE TE et al. Inhibition of angiogenesis by recombinant human platelet factor 4 and related, peptides. Science 247: 77-79, 1990.

76 - SAVILLE MW et al. Treatment of HIV-associated Kaposi's sarcoma with paclitaxel. Lancet 346: 26-28, 1995.

77 - WITZKE O et al. Beta-human choriogonadotropin therapy and HIV-related Kaposi's sarcoma. Eur J Med Res 2: 155158, 1997.

Recebido para publicação em 23/02/99

Aprovado para publicação em 09/03/99 